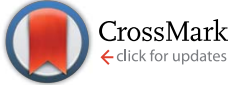

Cite this: RSC Adv., 2016, 6, 71262

\title{
Elucidation of the mechanisms governing the thermal diastereomerization of bioactive chiral 1,3,4-thiadiazoline spiro-cyclohexyl derivatives towards their anancomeric stereoisomers $\uparrow$
}

\begin{abstract}
S. Menta,,$^{a}$ S. Carradori,,$^{b}$ G. Siani, ${ }^{\text {b }}$ D. Secci, ${ }^{a}$ L. Mannina, ${ }^{a}$ A. P. Sobolev, ${ }^{\text {c }}$ R. Cirillid and M. Pierini ${ }^{\star a}$

The kinetics of the thermal isomerization of some diastereomers of three chiral 1,3,4 thiadiazoline derivatives, selected as case studies of structures resulting from mono-alkyl substitution of the anancomeric 4-acetyl-2-acetamido-1,3,4-thiadiazolinyl-spiro-cyclohexane (TsC) framework, have been investigated in order to elucidate the possible mechanistic pathways and the structural factors responsible for the observed spiro-junction lability. The insertion of a methyl or a $t$-butyl group on the C2 or C3 position with respect to the spiro junction generates two stereogenic centres, so that two pairs of enantiomers exist. The first-order rate constants for the isomerization of the less stable enantiomers into the most stable ones have been measured in different solvents and at different temperatures through batch-wise kinetic determinations. The obtained data have been successfully rationalized by DFT calculations and Linear Solvation Energy Relationships (LSER) analyses. The achieved elucidation should make it possible to plan a more rational synthesis of this kind of pharmacologically active compounds, thus affording a practical tool that is useful for controlling the involved stereochemistry and spiro-junction lability.
\end{abstract}

Received 26th May 2016

Accepted 19th July 2016

DOI: $10.1039 / c 6 r a 13727 j$

www.rsc.org/advances

\section{Introduction}

The biological activity expressed by natural or synthetic products can be frequently ascribed to specific molecular frameworks, which are typically referred to as "pharmacophores". Among these, heterocyclic moieties are quite common, covering a very wide range of pharmacological activities despite of their rather essential structure..$^{1-20}$

In addition to the electronic effects exerted by groups substituting the heterocyclic moiety, the manifested biological activity can also derive from the particular stereochemistry ${ }^{21}$ and structural rigidity characterizing the pharmacophoric

${ }^{a}$ Dipartimento di Chimica e Tecnologie del Farmaco, Sapienza Università di Roma, P.le Aldo Moro 5, 00185 Rome, Italy.E-mail: marco.pierini@uniroma1.it

${ }^{b}$ Department of Pharmacy, “G. D'Annunzio" University of Chieti-Pescara, Via dei Vestini 31, 66100 Chieti, Italy

"Laboratorio di Risonanza Magnetica "AnnalauraSegre", Istituto di Metodologie Chimiche CNR Area della Ricerca di Roma, Via Salaria km 29.300, 00015 Monterotondo, Italy

${ }^{d}$ Dipartimento del Farmaco, Istituto Superiore di Sanità, Viale Regina Elena, 299, o0161 Rome, Italy. E-mail: roberto.cirilli@iss.it

$\dagger$ Electronic supplementary information (ESI) available: Table of absolute energy stabilities computed for compounds L-1/L-3 and models TsC; table of results of the LSER analyses carried out on compounds L-1/L-3; Cartesian coordinates of the computed GS and TS structures. See DOI: 10.1039/c6ra13727j

\$ Sergio Menta and Simone Carradori contributed equally to this work. portion that interacts with the target active site, ${ }^{22-25}$ as observed, for example, for some classes of spiro-heterocycles. ${ }^{26-32}$

Spiro-1,3,4-thiadiazoline derivatives, endowed with antiinflammatory, analgesic, antifungal and/or antimicrobial activities, ${ }^{33-36}$ represent significant examples of biologically active heterocyclic compounds in which the 1,3,4-thiadiazoline ring and the connected rigid spiro-structure act as a single 'hybrid pharmacophore' framework. We have recently reported $^{36}$ a quite in depth thermodynamic study focused to clarify the thermodynamic and stereochemical properties possessed by the chiral 1,3,4-thiadiazoline-spiro-cyclohexyl derivatives 1-3, reported in Fig. 1, obtained by mono-alkyl (methyl or $t$-butyl) substitution at the position 2 or 3 of the cyclohexyl ring within the 4-acetyl-2-acetamido-1,3,4thiadiazolinyl-spiro-cyclohexane molecular framework (TsC, Fig. 1). The insertion of the alkyl group generates two asymmetric centres, i.e. the carbon atom on which the alkyl is bound and the carbon involved in the spiro junction (hereafter symbolized as $\mathrm{C}_{\text {spiro }}$ ). We highlighted the anancomeric ${ }^{37,38}$ character possessed by the TsC portion when its sulphur atom is bound in axial position $\left(\mathrm{S}_{\mathrm{ax}}\right)$ on the cyclohexyl moiety (TsC-S $\mathrm{S}_{\mathrm{ax}}$ conformation). The anancomerism of the TsC-S $S_{a x}$ framework was found to be at the origin of the very different energy stability characterizing the two typologies of diastereomers M-x and L-x, each of which exists as a couple of enantiomers (where $M$ and $L$ 

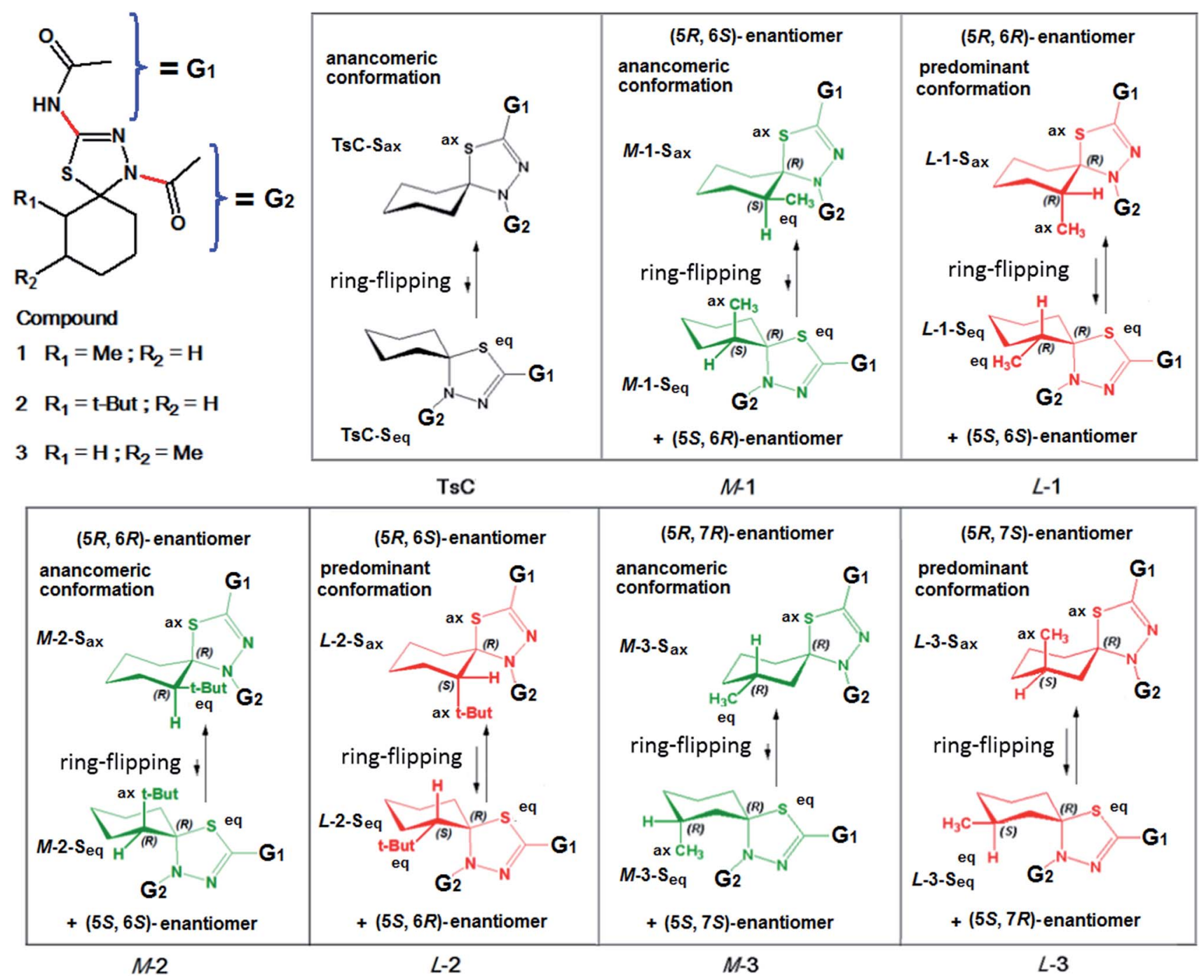

Fig. 1 Structures and conformational preferences of the 1,3,4-thiadiazoline-spiro-cyclohexyl derivatives studied in this work and of their common TsC framework.

indicate the more and the less stable diastereomers, respectively, with $\mathbf{x}$ referring to the species 1-3). The most stable diastereomers $\mathbf{M}-\mathbf{x}$ in their most favourable $\mathrm{S}_{\mathrm{ax}}$ conformation also possess anancomeric character $(100 \%$ of Boltzmann population, BP), with the alkyl group always disposed in equatorial position $\left(\mathrm{M}-\mathrm{x}-\mathrm{S}_{\mathrm{ax}}\right)$. For the less stable diastereomers $\mathrm{L}-\mathrm{x}$, the $\mathrm{S}_{\mathrm{ax}}$ conformation with the alkyl moiety in axial position $\left(\mathrm{L}-\mathrm{x}-\mathrm{S}_{\mathrm{ax}}\right)$ is again energetically favoured on that generated by cyclohexylflipping, with the sulphur atom in equatorial position (L-x$\mathrm{S}_{\mathrm{eq}}$ ), although in this case BP is lesser than $100 \%$. NMR, X-ray determinations and Density Functional Theory (DFT) calculations ${ }^{36}$ confirmed the predominance of the $S_{\text {ax }}$ conformations in compounds L-x even in the case of substitution with the sterically much hindered $t$-butyl group ${ }^{37}$ (compound L-2).

The dominance of the $S_{\text {ax }}$ on the $S_{\text {eq }}$ conformations, due to the $\mathrm{S} \cdots \mathrm{H}$ and $\mathrm{O} \cdots \mathrm{H}$ steric interactions more destabilizing the latter structures than the former ones, ${ }^{36}$ is also visible in the $\mathrm{X}$ ray structures of some other 1,3,4-thiadiazolinyl-spirocyclohexane derivatives reported in literature, ${ }^{33,34}$ so that such a conformational preference could be considered as a general rule.

In the present study the previously highlighted tendency of compounds L-x to lose the configuration of their asymmetric spiro-carbon, to give rise to the relevant diastereomers $\mathbf{M}-\mathbf{x},{ }^{36}$ has been in-depth investigated. This was made in order to clarify the mechanistic pathway governing the isomerization processes, and the structural factors (i.e. the nature and the position of the alkyl substitution) responsible for the observed stereolability. In our opinion, these informations could play an important role in the development of the stereoselective synthesis of M-x or L-x species, addressing the operative conditions towards a thermodynamic or kinetic control of the reaction, respectively. For this purpose, we carried out extensive kinetic batch-wise determinations in different conditions of solvent and temperature. The obtained results have been rationalized by DFT molecular modeling calculations and LSER analyses, which allowed to elucidate the specific solvent effect on the kinetic of the studied isomerizations. 


\section{Experimental}

\section{Organic synthesis of compounds L-1, L-2 and L-3}

Compounds L-1, L-2 and L-3 have been synthesized according to the procedure already reported in ref. 36 and schematized in Scheme 1, adopting conditions suitable to favor a kinetic control.

\section{Chiral HPLC}

HPLC enantioseparations and diastereoseparations were performed by using the stainless-steel Chiralpak IC ${ }^{39-42}(250 \mathrm{~mm} \times$ $4.6 \mathrm{~mm}$ I.D. and $250 \mathrm{~mm} \times 10 \mathrm{~mm}$ I.D.) (Chiral Technologies Europe, Illkirch, France) columns. All HPLC and spectral grade solvents were purchased from Aldrich (Italy) and used without further purification. The analytical HPLC apparatus consisted of a PerkinElmer (Norwalk, CT, USA) 200 lc pump equipped with a Rheodyne (Cotati, CA, USA) injector, a $20 \mu \mathrm{L}$ sample loop, a HPLC Dionex CC-100 oven (Sunnyvale, CA, USA) and a Jasco (Jasco, Tokyo, Japan) Model CD 2095 Plus UV/CD detector. For semipreparative separations a PerkinElmer 200 LC pump equipped with a Rheodyne injector, a $500 \mu \mathrm{L}$ sample loop, a PerkinElmer LC 101 oven and Waters 484 detector (Waters Corporation, Milford, MA, USA) were used. The signal was acquired and processed by Clarity software (DataApex, Prague, The Czech Republic).

\section{Off-column diastereomerization studies}

In off-column diastereomerization studies, solutions of stereoisomers of 1-3 (concentration about $0.1 \mathrm{mg} \mathrm{ml}^{-1}$ ) were kept at a fixed temperature in a closed vessel. The temperature was monitored by a Julabo (Julabo Labortechnik, Seelbach, Germany) Model HP-4 thermostat. Samples were withdrawn at fixed time intervals and analyzed by HPLC on the Chiralpak IC (250 $\mathrm{mm} \times 4.6 \mathrm{~mm}$ I.D) column.

\section{Stereochemical lability (rate constants determination): experimental procedure}

Starting from the $(5 S, 6 R)-\mathrm{L}-2$ isomer, the L-2 $\rightarrow$ M-2 isomerizations in EA and IPA at the temperature of $55{ }^{\circ} \mathrm{C}$ were monitored almost until the respective thermodynamic equilibrium was achieved. This was done following the same procedure adopted for the analogous determinations, reported in ref. 36, which were performed in $\mathrm{CHCl}_{3}$ and $\mathrm{AA}$ solutions at $55{ }^{\circ} \mathrm{C}$ for the L-1, L-2 and L-3 isomers. Accordingly, the collection of

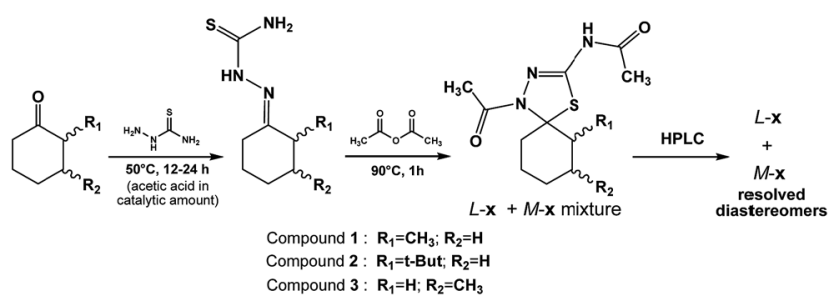

Scheme 1 Synthetic procedure adopted to obtain compounds L-1, L2 and L-3. kinetic data was interrupted when the $[\mathrm{M}]_{\mathrm{eq}} /[\mathrm{L}]_{\mathrm{eq}}$ ratio became lesser than 0.5 , because of the difficulty to obtain accurate values of area subtended by the decreasing peak. Therefore, the sought constants $K_{\text {eq }}$ were derived through careful extrapolation procedure, by maximizing the correlation coefficient $\left(R^{2}\right.$ always greater than 0.999 ) of graphs traced according to eqn (1) (see below), in which the term $-K_{\text {eq }} /\left(K_{\text {eq }}+1\right) \times \ln \left([\mathrm{L}]_{0}-[\mathrm{L}]_{\mathrm{eq}}\right) /\left([\mathrm{L}]_{t}-\right.$ $\left.[\mathrm{L}]_{\mathrm{eq}}\right)$ was plotted against the reaction time. From the slope of the same plots the values of the $k_{\mathrm{L} \rightarrow \mathrm{M}}$ rate constants were also obtained, as well as the relevant backward rate constants $k_{\mathrm{M} \rightarrow \mathrm{L}}$ by resorting to the relation $k_{\mathrm{M} \rightarrow \mathrm{L}}=k_{\mathrm{L} \rightarrow \mathrm{M}} / K_{\text {eq }}$. Instead, in order to limit the very expensive time required by this kind of determinations, for $(5 S, 6 S)-\mathrm{L}-1$ and $(5 R, 7 S)-\mathrm{L}-3$ and in the two solvents EA and IPA the off-column measurements at $55^{\circ} \mathrm{C}$ were carried out by restricting the collection of isomerisation data to a minimal number, quite far from the thermodynamic equilibrium. In this way, only $k_{\mathrm{L} \rightarrow \mathrm{M}}$ rate constants could be measured through suitable analysis of the initial reaction steps. These were obtained through graphs in which the $\ln \left([\mathrm{L}]_{0} /[\mathrm{L}]_{t}\right)$ quantities were plotted versus the reaction times, according to the following equation: $\ln \left([\mathrm{L}]_{0} /[\mathrm{L}]_{t}\right)=-k_{\mathrm{L} \rightarrow \mathrm{M}} \times t$, which governs irreversible first-order kinetic pathways.

Finally, this same last simplified approach was also employed to determine the $k_{\mathrm{L} \rightarrow \mathrm{M}}$ rate constants in experiments performed on $(5 S, 6 S)$-L-1, $(5 S, 6 R)-\mathrm{L}-2$ and $(5 R, 7 S)-\mathrm{L}-3$ in AA at temperatures greater than $55{ }^{\circ} \mathrm{C}$ (see Table 1 ). Starting from all the measured $\mathrm{L} \rightarrow \mathrm{M}$ and $\mathrm{M} \rightarrow \mathrm{L}$ diastereomerization rate constants, they were then calculated the related free energy activation barriers (i.e. the $\Delta G_{\mathrm{L} \rightarrow \mathrm{M}(T)}^{\#}$ and $\Delta G_{\mathrm{M} \rightarrow \mathrm{L}(T)}^{\#}$ quantities) (Table 1 in main text).

\section{LSER analyses}

LSER analyses of the activation energy data $\Delta G_{\mathrm{L} \rightarrow \mathrm{M}}^{\#}$ calculated for compounds L-1, L-2 and L-3, were performed according to the Kamlet-Taft type eqn (2) (see below) taking into account one or two of the chosen three descriptors $\pi^{*}, \varepsilon$ and $\delta_{\mathrm{H}}{ }^{2}$ of solvent effect. A statistic analysis ( $F$-test and $t$-test) was carried out, in order to exclude casualness (index- $F$ ) and quantify the statistical weight of each employed descriptor (factors $t_{\mathrm{i}}$ compared to index- $T$ used as the reference). The analyses were performed by the dedicated functions implemented in the Microsoft Office Excel 2003 program. Probability related to the $t$-Student distribution in the $t$-test was set to 0.15 . The obtained results, collected in Table S3 of ESI $\dagger$ clearly show that good correlations ( $R^{2}$ values ranging from 0.823 to 0.938 ) can be obtained for all the three compounds L-1, L-2 and L-3, when the descriptor $\pi^{*}$ is used as unique parameter. Statistical analysis highlighted that significant results are obtained when the couple of descriptors $\pi^{*}, \varepsilon$ or $\varepsilon, \delta_{\mathrm{H}}{ }^{2}$ are taking into account in eqn (2) only when the regression analysis is carried out on $\Delta G_{\mathrm{L} \rightarrow \mathrm{M}}^{\#}$ data of compounds L-1 and L-3.

\section{Molecular modeling calculations}

All calculations were performed with the software package SPARTAN 10, v. 1.1.0. The structures of the transition states of the spiro-thiadiazoline derivatives L-1, L-2 and L-3, as well as 
Table 1 Kinetic results of the thermal diastereomerization of L-1, L-2 and L-3 monitored by stereoselective HPLC

\begin{tabular}{|c|c|c|c|c|c|c|c|c|}
\hline \# & Solvent & $T\left({ }^{\circ} \mathrm{C}\right)$ & $k_{\mathrm{L} \rightarrow \mathrm{M}}\left(\mathrm{s}^{-1}\right)$ & $k_{\mathrm{M} \rightarrow \mathrm{L}}\left(\mathrm{s}^{-1}\right)$ & $\Delta G_{\mathrm{L} \rightarrow \mathrm{M}}^{\#}\left(\mathrm{kcal} \mathrm{mol}^{-1}\right)$ & $\Delta G_{\mathrm{M} \rightarrow \mathrm{L}}^{\#}\left(\mathrm{kcal} \mathrm{mol}^{-1}\right)$ & $\Delta G_{\mathrm{M} \leftrightarrows \mathrm{L}}^{\circ}\left(\mathrm{kcal} \mathrm{mol}^{-1}\right)$ & $t_{1 / 2} \mathrm{~L} \rightarrow \mathrm{M}^{a}$ \\
\hline \multirow[t]{5}{*}{1} & $\mathrm{CHCl}_{3}{ }^{b}$ & 55 & $8.22 \times 10^{-6}$ & $1.23 \times 10^{-8}$ & 26.90 & 31.14 & -4.24 & $1 \mathrm{~d}$ \\
\hline & EA & 55 & $9.43 \times 10^{-7}$ & - & 28.32 & - & - & $9 \mathrm{~d}$ \\
\hline & $\mathrm{AA}^{b}$ & 55 & $2.11 \times 10^{-6}$ & $1.68 \times 10^{-8}$ & 27.79 & 30.94 & -3.15 & $4 \mathrm{~d}$ \\
\hline & $\mathrm{AA}$ & 65 & $9.09 \times 10^{-6}$ & - & 27.68 & - & - & $21 \mathrm{~h}$ \\
\hline & AA & 75 & $2.54 \times 10^{-5}$ & - & 27.79 & - & - & $455 \mathrm{~min}$ \\
\hline \multirow[t]{6}{*}{2} & $\mathrm{CHCl}_{3}{ }^{b}$ & 55 & $6.68 \times 10^{-5}$ & $2.67 \times 10^{-9}$ & 25.54 & 32.14 & -6.60 & $174 \mathrm{~min}$ \\
\hline & EA & 55 & $9.00 \times 10^{-6}$ & $5.40 \times 10^{-9}$ & 26.85 & 31.68 & -4.83 & $21 \mathrm{~h}$ \\
\hline & IPA & 55 & $2.16 \times 10^{-6}$ & $3.96 \times 10^{-8}$ & 27.78 & 30.38 & -2.60 & $93 \mathrm{~h}$ \\
\hline & $\mathrm{AA}^{b}$ & 55 & $5.06 \times 10^{-5}$ & $1.57 \times 10^{-7}$ & 25.72 & 29.48 & -3.76 & $248 \mathrm{~min}$ \\
\hline & $\mathrm{AA}$ & 65 & $1.67 \times 10^{-4}$ & - & 25.72 & - & - & $69 \mathrm{~min}$ \\
\hline & AA & 75 & $4.72 \times 10^{-4}$ & - & 25.78 & - & - & $25 \mathrm{~min}$ \\
\hline & $\mathrm{AA}^{b}$ & 55 & $2.72 \times 10^{-5}$ & $2.58 \times 10^{-7}$ & 26.12 & 29.16 & -3.04 & $533 \mathrm{~min}$ \\
\hline & $\mathrm{AA}$ & 65 & $7.34 \times 10^{-5}$ & - & 26.27 & - & - & $157 \mathrm{~min}$ \\
\hline & $\mathrm{AA}$ & 75 & $2.20 \times 10^{-4}$ & - & 26.31 & - & - & $52 \mathrm{~min}$ \\
\hline & AA & 85 & $6.99 \times 10^{-4}$ & - & 26.26 & - & - & $17 \mathrm{~min}$ \\
\hline & $\mathrm{AA}$ & 95 & $1.60 \times 10^{-3}$ & - & 26.41 & - & - & $7 \mathrm{~min}$ \\
\hline
\end{tabular}

those of the TsC framework, involved in the Step I of the general reaction pathway, were modelled in two steps. In the first one SCF structure optimizations were performed at the HF/3-21G level of theory. In the second step, the obtained geometries were refined through further optimization at the B3LYP/6$31 \mathrm{G}(\mathrm{d})$ level of theory and validated as saddle points by checking the presence among the computed vibrational modes of only one imaginary frequency, just corresponding to the rupture-formation of the $\mathrm{S}-\mathrm{C}_{\text {spiro }}$ bonds. The structures of the ground and the transition states relevant to Step II of the general reaction pathway and referred to the species $\mathrm{L}-\mathbf{1}-\mathrm{ZW}-\mathrm{S}_{\mathrm{eq}}$, L-1-ZW-S $\mathrm{ax}_{\mathrm{ax}}$ L-2-ZW-S $\mathrm{S}_{\mathrm{eq}}$ L-2-ZW-S ${ }_{\mathrm{ax}}$, TsC-ZW-S $\mathrm{eq}_{\mathrm{eq}}$ and TsC-ZW-S were modelled by driving the progressive change of the torsional angle $\mathrm{N}-\mathrm{N}-\mathrm{C}_{\text {spiro }}-\mathrm{CH}$ as a function of the energy, according to the relevant algorithm implemented in SPARTAN 10 (i.e. the "Energy Profile" option inside the "Calculate" window). The rotation of the dihedral angle was performed by imposing an overall variation of $180^{\circ}$ trough a number of steps ranging from 15 to 17 . The optimization of the single structures, with imposed constraint for each set dihedral angle, was initially performed at the HF/3-21G level of theory. Afterwards, the achieved geometries corresponding to the minimum and maximum of the assessed energy profiles have also been submitted to further optimization through the B3LYP/6-31G(d) method. In all cases, the optimization procedure was carried out by simulating chloroform as the medium, according to the SM8 solvation model implemented in Spartan. Only for the GS

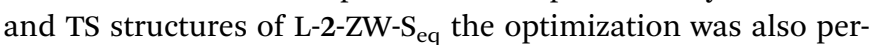
formed by simulating the presence of ethyl acetate or 2-propanol as the solvent, again according to the SM8 solvation model implemented in Spartan. Finally, in order to take into suitable account non-bonding interactions, all the obtained GS and TS geometries were also submitted to single point energy calculations, each one carried out in the same solvent used in their optimization (chloroform, ethyl acetate or 2-propanol), at the higher level of theory M06-2X/6-31+G(d). The use of the M06-2X method was suggested by the need to take into suitable account in the assessed total energy of the structures the not negligible contribution coming from dispersive forces, being, in fact, M062X a meta-hybrid GGA DFT functional known to have a very good response under dispersion forces. ${ }^{4-46}$ The diastereomerization barriers of compounds L-1, L-2 and L-3 in aqueous medium were assessed by directly reoptimizing in water (according to the SM8 solvation model), at the B3LYP/6-31G(d) level of theory, the GS and TS geometries already found responsible for the rate-limiting steps in chloroform. The so obtained structures were then submitted to single point energy calculations at the higher level of theory M06-2X/6-31+G(d).

\section{Results and discussion}

The fact that in the compounds $\mathbf{M}-\mathbf{x}$ and L-x the TsC fragment takes the $S_{a x}$ conformation implies that the alkyl groups bound on the cyclohexane moiety have necessarily to assume the equatorial position in case of the most stable diastereomers $\mathbf{M}$ $\mathbf{x}-\mathrm{S}_{\mathrm{ax}}$, and the axial position in case of the less stable diastereomers $L-x-S_{a x}$. This was found true even in the case of the very highly hindered $t$-butyl group in compound L-2. ${ }^{36}$

It is useful to stress that the lower stability of the $\mathrm{L}-\mathrm{x}-\mathrm{S}_{\mathrm{ax}}$ stereoisomers (of 3.2, 3.8 and $3.0 \mathrm{kcal} \mathrm{mol}^{-1}$ in acetic 
anhydride, for compound 1, 2 and 3, respectively ${ }^{36}$ ) may potentially act as a driving force to the spontaneous conversion of the species to the related $\mathbf{M}-\mathbf{x}-\mathrm{S}_{\mathrm{ax}}$ diastereomers. This was actually observed in both acetic anhydride (AA) and chloroform $\left(\mathrm{CHCl}_{3}\right)$, at the temperature of $55{ }^{\circ} \mathrm{C} .{ }^{36}$ With the aim to gain a larger and complete mechanistic picture, the kinetic investigation was extended to a large number of solvents and temperatures.

\section{Stereochemical lability of the species L-x: experimental investigation}

The kinetic analysis of the stereolability of the species L-1, L-2 and L-3 at $55{ }^{\circ} \mathrm{C}$ has been extended to ethyl acetate (EA) and isopropyl alcohol (IPA) as the solvents, while in AA the range of temperatures was extended from $65{ }^{\circ} \mathrm{C}$ to $95{ }^{\circ} \mathrm{C}$. The timedependent decay of the diastereomeric excess of the L-x stereoisomers was evaluated by classical batch-wise kinetic approach, as previously reported, ${ }^{36}$ using the stereoselective HPLC technique as the monitoring tool. ${ }^{19,47-49}$

All the reactions proceeded according to a reversible firstorder kinetic (eqn (1)):

$$
\ln \left([\mathrm{L}]_{0}-[\mathrm{L}]_{\mathrm{eq}}\right) /\left([\mathrm{L}]_{t}-[\mathrm{L}]_{\mathrm{eq}}\right)=-k_{\mathrm{L} \rightarrow \mathrm{M}} \times\left(K_{\mathrm{eq}}+1\right) / K_{\mathrm{eq}} \times t
$$

in which: $K_{\text {eq }}$ is the equilibrium constant for the $\mathrm{L} \leftrightarrows \mathrm{M}$ interconversion (i.e. $K_{\mathrm{eq}}=[\mathrm{M}]_{\mathrm{eq}} /[\mathrm{L}]_{\mathrm{eq}}$, with $[\mathrm{M}]_{\mathrm{eq}}$ and $[\mathrm{L}]_{\mathrm{eq}}$ being the concentrations of the species at equilibrium); $k_{\mathrm{L} \rightarrow \mathrm{M}}$ is the first order rate constant for the forward reaction; $[\mathrm{L}]_{0}$ and $[\mathrm{L}]_{t}$ are the concentrations of the $\mathrm{L}$ isomer at time zero and time $t$, respectively. The graph of Fig. $2 \mathrm{~b}$, obtained by plotting the percentage-amount of $(5 S, 6 S)-\mathrm{L}-\mathbf{1}$ against the reaction time, shows the typical trend of a reversible first-order process that achieve a final equilibrium position strongly favorable to the $\mathbf{M}$ product (virtually, an irreversible process). The forward and backward rate constants, $k_{\mathrm{L} \rightarrow \mathrm{M}}$ and $k_{\mathrm{M} \rightarrow \mathrm{L}}$, and the related activation energies, for the species L-1, L-2 and L-3 have been collected in Table 1 . In all cases it was found that the conversions of L-x in M-x occur without any concomitant racemization,

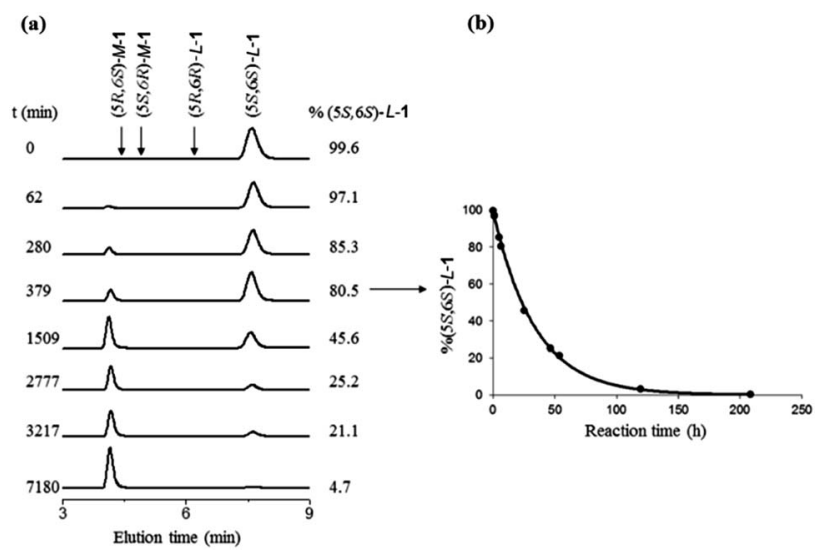

Fig. 2 (a) Off-column diastereomerization at $55^{\circ} \mathrm{C}$ in chloroform by HPLC (see also ref. 36) and (b) time-dependent decay of the amount of $(5 S, 6 S)-L-1$. i.e. the isomerization process involves only the stereogenic center $\mathrm{C}_{\text {spiro, }}$, while the asymmetric carbon atom of the cyclohexyl fragment retains its absolute configuration. This conclusion was supported by the analysis of the chromatograms recorded as a function of time in the course of the performed off-column isomerizations. As an example, the distereomerization in chloroform solution at $55{ }^{\circ} \mathrm{C}$ of the isomer $(5 S, 6 S)-\mathrm{L}-\mathbf{1}$, the fourth in order of elution, is reported in Fig. 2a.

As the peak corresponding to $(5 S, 6 S)$-L-1 decreases, the peak corresponding to its diastereoisomer $(5 R, 6 S)-\mathrm{M}-1$, the first in order of elution, increases, and the diastereomeric ratio progressively changes over the reaction time. The lack in all the chromatographic patterns of the peaks corresponding to the two stereoisomers $(5 S, 6 R)-\mathrm{M}-1$ and $(5 R, 6 R)-\mathrm{L}-\mathbf{1}$, excludes the occurrence of an inversion of configuration at the asymmetric carbon C6.

The same trend was observed in all the performed offcolumn L-x $\rightarrow$ M-x kinetic determinations, for all the analyzed compound, L-x, and solvent $\left(\mathrm{CHCl}_{3} \mathrm{AA},{ }^{36} \mathrm{EA}\right.$ or IPA).

From the data collected in Table 1 some other conclusions could be also inferred:

(i) the related barriers for $\mathrm{L}-\mathbf{x} \rightarrow \mathbf{M}$-x diastereomerization are virtually temperature-independent (see data obtained in AA), which indicates a negligible entropy contribution. This suggests that the isomerization mechanisms are based on true first-order kinetics $^{50-55}$ (i.e. a monomolecular step must be the slow-stage of the reactions);

(ii) for all the three compounds L-x, regardless of the solvent and temperature, the activation barriers of the L-x $\rightarrow \mathbf{M - x}$ processes are significantly high, with values equal or greater than $25.5 \mathrm{kcal} \mathrm{mol}^{-1}$. Obviously, the energy barriers for the backward $\mathrm{M}-\mathbf{x} \rightarrow$ L-x reactions are even higher (from $\sim 3$ to $\sim 7$ additional kcal $\mathrm{mol}^{-1}$, depending on compound and solvent). This means that, due to the large difference in energy stability that in all the cases has been found between the L-x-S $S_{a x}$ and the anancomeric $\mathbf{M}-\mathbf{x}-\mathrm{S}_{\mathrm{ax}}$ diastereomers, all the $\mathrm{L}-\mathbf{x} \rightarrow \mathbf{M}-\mathbf{x}$ investigated processes may be considered virtually irreversible (Table 1). Considering the temperature-independence of the $\Delta G_{\mathrm{L} \rightarrow \mathrm{M}}^{\#}$, we can assess that at $25^{\circ} \mathrm{C}$, in $\mathrm{AA}$, these isomerizations have very long half-life times $\left(t_{1 / 2}\right): 9$ months for L-1, 9 days for L-2 and 22 days for L-3. In other words, all the above three species can be considered reasonably stereo-stable at room temperature;

(iii) the rate of the diastereomerization process critically depends on the steric hindrance of the alkyl group bonded to the cyclohexane ring, as well as by the position of this group with respect to the spiro-centre. The comparison between the kinetic data relative to compounds L-1 and L-2 shows that, in the presence of the more bulky $t$-butyl group as the substituent, the isomerisation process is about ten times faster than in the presence of the much less bulky methyl group. Actually, the half-life times of the L-1 $\rightarrow$ M-1 and M-1 $\rightarrow$ L-1 processes in chloroform at $55{ }^{\circ} \mathrm{C}$ are 1 day and 483 days, respectively, and 3 hours and 30 days for the L-2 $\rightarrow$ M-2 and M-2 $\rightarrow$ L-2 processes in the same experimental conditions. As far as the effect of the position of the alkyl substitution, the obtained results were really surprising. In fact, despite of the greater distance from 
the reaction centre that the alkyl substituent has in L-3, the rate constants of the isomerization reaction of the compound L-3 were found very close to those obtained for the compound L-2, and markedly higher than those measured for the constitutional isomer L-1.

\section{Diastereomerization mechanism}

The evidence that the isomerisation reaction follows a firstorder kinetic suggests that molecules of solvent are not directly involved in the slow-stage, nor are active bimolecular autocatalytic phenomena. Therefore, we designed a series of deepened DFT molecular modelling calculations (carried out using chloroform as solvent of reference) with the aim to relate the experimental $\Delta G_{\mathrm{L} \rightarrow \mathrm{M}}^{\#}$ data determined for compounds L-x (Table 1) with monomolecular processes able to explain the observed change of configuration of the $\mathrm{C}_{\text {spiro }}$ centres. $\mathrm{A}$ mechanistic pathway that meets this requirement should take place in two sequential steps:

(Step I) an initial opening of the thiadiazoline-cycle at the $\mathrm{N}-$ $\mathrm{C}_{\text {spiro }}$ or $\mathrm{S}-\mathrm{C}_{\text {spiro }}$ bond, which generates a zwitterionic fragment (the thiadiazo-arm moiety hereafter denoted as ZW-F), still linked to $\mathrm{C}_{\text {spiro; }}$;

(Step II) the rotation of about $180^{\circ}$ of the $\mathrm{ZW}-\mathrm{F}$ fragment followed by a reclosing of the heterocyclic ring through a new $\mathrm{N}-\mathrm{C}_{\text {spiro }}$ or $\mathrm{S}-\mathrm{C}_{\text {spiro }}$ bond formation that inverts the original configuration of $\mathrm{C}_{\text {spiro }}$.

In this pathway, the slow step of the whole process could be the ring-opening (Step I) or the ZW-F-rotation (Step II, Schemes 2 and $\mathrm{S} 1$ in ESI $\dagger$ ). The DFT analysis was carried out by assessing the energy barriers for Step I and Step II. A detailed description of the computational procedures is reported in the $\mathrm{ESI}^{\dagger}$ together with the obtained results (Tables S1 and S2 $\dagger$ ). The calculations pointed out that the break of the $\mathrm{S}-\mathrm{C}_{\text {spiro }}$ bond is advantaged on that of the $\mathrm{N}-\mathrm{C}_{\text {spiro }}$ bond for not less than $32 \mathrm{kcal}$

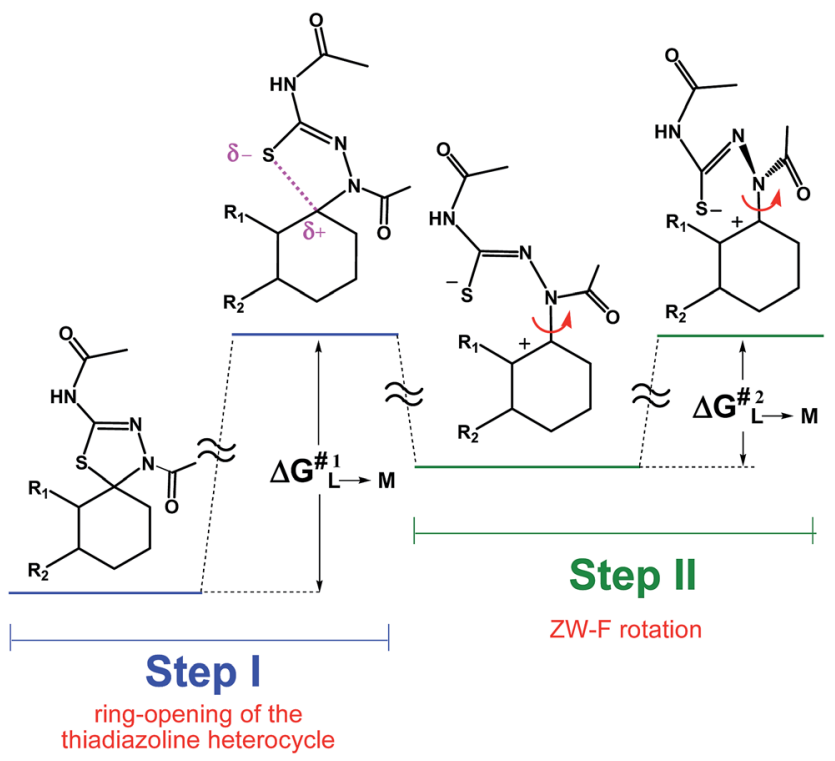

Scheme 2 Possible slow steps involved in the $L \rightarrow M$ diastereomerization mechanisms of compounds $L-x$. $\mathrm{mol}^{-1}$ (Table $\mathrm{S} 1 \dagger$ ). The higher $\Delta E_{\mathrm{L} \rightarrow \mathrm{M}}^{\#}$ barrier for the $\mathrm{S}-\mathrm{C}_{\text {spiro }}$ breaking was that estimated starting from the unsubstituted TsC framework in its anancomeric $\mathrm{S}_{\mathrm{ax}}$ conformation $\left(\Delta E_{\mathrm{L} \rightarrow \mathrm{M}}^{\#}=\right.$ $29.3 \mathrm{kcal} \mathrm{mol}^{-1}$, Table S2 $\uparrow$ and Schemes $3 \mathrm{a}$ and S2 in ESI $\dagger$ ). In compounds L-1, L-2 and L-3 the presence of a methyl or $t$-butyl group leads to significant structure perturbations that strongly compress the differences of energy stability existing between the two conformational ground states (GS) of $\mathrm{L}-\mathrm{x}-\mathrm{S}_{\mathrm{eq}}$ and $\mathrm{L}-\mathrm{x}-\mathrm{S}_{\mathrm{ax}}$ (from $5.25 \mathrm{kcal} \mathrm{mol}^{-1}$ for TsC to $1.83,0.24$ and $1.89 \mathrm{kcal} \mathrm{mol}^{-1}$ for L-1, L-2 and L-3, respectively). These results suggest that, inside the L-x species, the alkyl substitution has the effect to cancel the anancomeric character of the $\mathbf{T s C}-\mathrm{S}_{\mathrm{ax}}$ fragment. On the contrary, the same alkyl substitution increases the difference of energy stability between the related transition states, TS $\left(E_{\mathrm{TS}-\mathrm{L}-\mathrm{x}-\mathrm{Seq}}-E_{\mathrm{TS}-\mathrm{L}-\mathrm{x}-\mathrm{Sax}}\right.$, from $-0.30 \mathrm{kcal} \mathrm{mol}^{-1}$ for TsC to 4.39 , 5.63 and $-2.98 \mathrm{kcal} \mathrm{mol}^{-1}$ for L-1, L-2 and L-3, respectively). Obviously, these different effects of steric perturbation have also significant reflex on the related barriers with which the L-x species undergo ring-opening. In particular, with respect to what found for TsC-S $\mathrm{S}_{\mathrm{ax}}$ used as the reference, the assessed values of $\Delta E_{\mathrm{L} \rightarrow \mathrm{M}}^{\#}$ for the $\mathrm{S}-\mathrm{C}_{\text {spiro }}$ breaking in almost all the considered $\mathrm{L}-\mathrm{x}-\mathrm{S}_{\mathrm{ax}}$ and $\mathrm{L}-\mathrm{x}-\mathrm{S}_{\text {eq }}$ species, are smaller.

The estimated reduction of the barrier ranges from small for L-3-S ${ }_{\mathrm{ax}}\left(0.4 \mathrm{kcal} \mathrm{mol}^{-1}\right)$, to medium for L-2-S $\mathrm{eq}_{\text {and } \mathrm{L}-1-\mathrm{S}_{\mathrm{ax}}}(1.6$
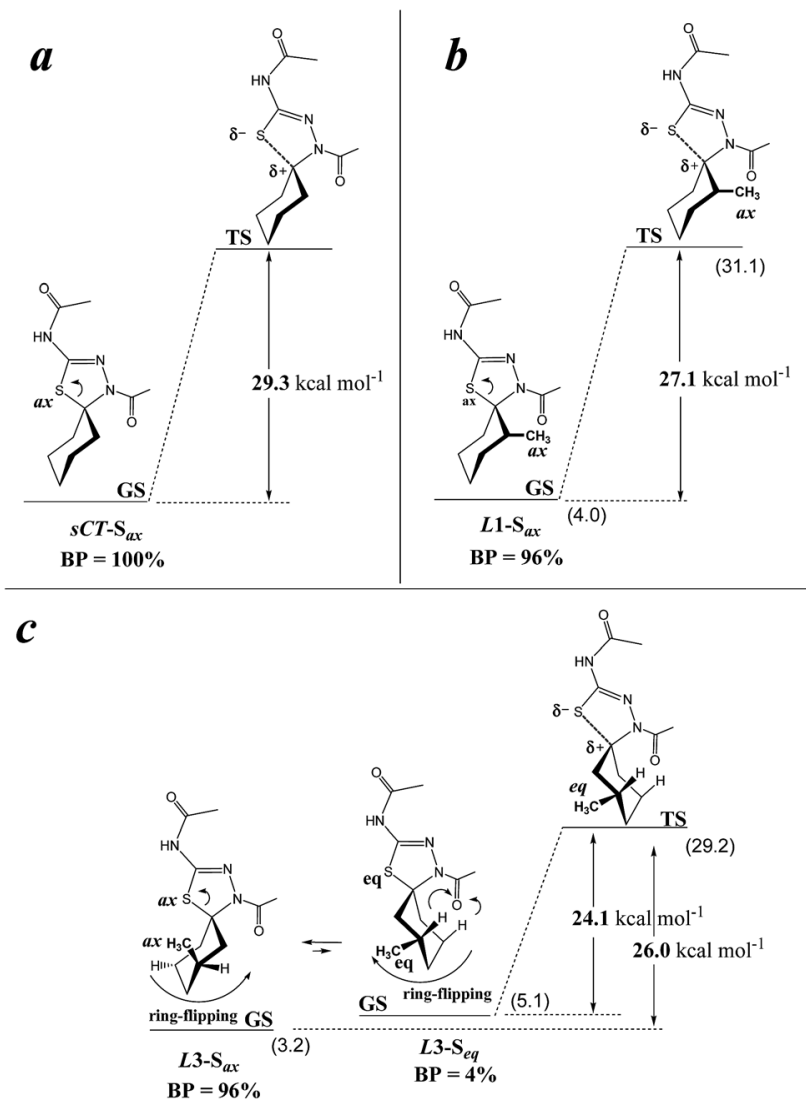

Scheme $3 \mathrm{~L} \rightarrow \mathrm{M}$ diastereomerization mechanisms of compounds TsC, L-1 and L-3 derived by DFT calculations. In parentheses are reported the relative energy stabilities in $\mathrm{kcal} \mathrm{mol}^{-1}$ of the species with respect to that of the relevant anancomeric $\mathrm{M}-\mathrm{x}-\mathrm{S}_{\mathrm{ax}}$ isomers. 
and $2.2 \mathrm{kcal} \mathrm{mol}^{-1}$, respectively) to very marked for L-2-S $\mathrm{ax}$ and L-3-S $\mathrm{S}_{\text {eq }}\left(7.0\right.$ and $5.2 \mathrm{kcal} \mathrm{mol}^{-1}$, respectively), while a little increase was observed for L-1-S ${ }_{\text {eq }}\left(-0.4 \mathrm{kcal} \mathrm{mol}^{-1}\right)$. In the case of the TsC-S $\mathrm{S}_{\mathrm{ax}}$ and TsC-S $\mathrm{S}_{\mathrm{eq}}$ conformers, calculations have also suggested that a negligible barrier opposes to the final reclousure of the thiadiazoline-cycle, starting from the related $\mathrm{ZW}-\mathrm{F}$ structures (about $1 \mathrm{kcal} \mathrm{mol}^{-1}$, Table $\mathrm{S} 2 \dagger$ ). Thus, for the purposes of the undertaken kinetic analyses, it seems logical to assume that also for the more complexes L-x $\rightarrow$ M-x processes such conclusive stage of the studied isomerizations can be reasonably disregarded. As it will be clarified in detail below, the $\mathrm{S}-\mathrm{C}_{\text {spiro }}$ bond breaking in Step I was found responsible for the $\mathrm{L} \rightarrow \mathrm{M}$ diastereomerization in both compounds L-1 and L-3, while the ZW-F rotation was found to govern the slow step of the $\mathrm{L} \rightarrow \mathrm{M}$ process for compound L-2.

\section{Diastereomerization mechanism of compounds L-1 and L-3}

The two $\Delta E_{\mathrm{L} \rightarrow \mathrm{M}}^{\#}$ barriers calculated for the compound $\mathrm{L}-\mathbf{1}$, starting from the conformers $\mathrm{L}-\mathbf{1}-\mathrm{S}_{\mathrm{eq}}$ and $\mathrm{L}-\mathbf{1}-\mathrm{S}_{\mathrm{ax}}$, are very different (29.7 and $27.1 \mathrm{kcal} \mathrm{mol}^{-1}$, respectively). Thus, we could expect that the more stable geometry (i.e. the $\mathrm{L}-\mathbf{1}-\mathrm{S}_{\mathrm{ax}}$ conformer, for which has been calculated a $96 \%$ of BP) is the one involved in the predicted ring-opening of Step I (Schemes 3b and S3 in ESI $\dagger$ ). It is noteworthy to emphasize that the so calculated datum differs from the experimental one $(26.90 \mathrm{kcal}$ $\mathrm{mol}^{-1}$ ) for just $0.2 \mathrm{kcal} \mathrm{mol}^{-1}$. Differently, in the L-3 $\rightarrow \mathrm{M}-3$ isomerization process, the less stable conformer $\mathrm{L}-3-\mathrm{S}_{\mathrm{eq}}(\mathrm{BP}=$ $4 \%$, see ESI $\dagger$ ) undergoes the ring-opening with an activation energy of only $24.1 \mathrm{kcal} \mathrm{mol}^{-1}$, while for the more stable ringflipped conformer L-3-S $\mathrm{Sx}_{\mathrm{ax}}(\mathrm{BP}=96 \%$, Schemes $3 \mathrm{c}$ and $\mathrm{S} 4$ in ESI $\dagger$ ) the estimated barrier is of $28.9 \mathrm{kcal} \mathrm{mol}^{-1}$. Thus, for the species L-3 the most favourable $\mathrm{S}-\mathrm{C}_{\text {spiro }}$ breaking should involve the less stable isomer L-3-S $\mathrm{S}_{\text {eq }}$, which, in turn, through a fast conformational ring-flipping, should be continuous regenerated from the most abundant conformer L-3-S $\mathrm{S}_{\mathrm{ax}}$. The different behaviour observed for compounds L-1 and L-3 is attributable to the different effect exerted by the methyl group on the transition states of the ring-opening steps. Indeed, as already stressed above, for compound L-3 the difference of energy stability decreases of $2.98 \mathrm{kcal} \mathrm{mol}^{-1}$ on passing from the TS geometry relative to $\mathrm{L}-3-\mathrm{S}_{\mathrm{ax}}$ to that relative to $\mathrm{L}-3-\mathrm{S}_{\mathrm{eq}}$ while for compound L-1 the same energy difference increases of $4.39 \mathrm{kcal}$ $\mathrm{mol}^{-1}$. On the contrary, the estimated differences of energy stability between the $S_{\text {ax }}$ and $S_{\text {eq }}$ ground state geometries appear very similar (1.89 $\mathrm{kcal} \mathrm{mol}^{-1}$ for L-3, and $1.83 \mathrm{kcal} \mathrm{mol}^{-1}$ for L-1) so that no significant differential steric effect is evidenced for them. Additional details have been highlighted and discussed in ESI, $\uparrow$ in the section "The differential role played by the methyl group in compounds L-1 and L-3". On the basis of the above considerations, the final assessment of the energy barrier for the Step I of the L-3 $\rightarrow$ M-3 diastereomerization process requires to take into suitable consideration both the barrier of ring-opening for the geometry $\mathrm{L}-3-\mathrm{S}_{\mathrm{eq}}\left(24.1 \mathrm{kcal} \mathrm{mol}^{-1}\right)$ and the relative abundances of the conformers L-3-S $\mathrm{S}_{\mathrm{ax}}$ and L-3-S $(96 \%$ and $4 \%$ of BP, respectively; see ESI $\dagger$ ). Therefore, starting from such data, the time-dependent decay of L-3 (Fig. S2 in ESI†) was successfully simulated through the software Achem, ${ }^{\mathbf{5 6}}$ thus allowing the final assessment of the associated $\mathrm{S}-\mathrm{C}_{\text {spiro }}$ breaking activation energy, amounting to $26.0 \mathrm{kcal} \mathrm{mol}^{-1}$. Then, as found for L-1, also for L-3 the difference between calculated $\Delta E_{\mathrm{L} \rightarrow \mathrm{M}}^{\#}\left(26.0 \quad \mathrm{kcal} \quad \mathrm{mol}^{-1}\right)$ and experimental $\Delta G_{\mathrm{L} \rightarrow \mathrm{M}}^{\#}\left(25.5 \mathrm{kcal} \mathrm{mol}^{-1}\right)$ barriers appears very moderate. Interestingly, for both compounds L-1 and L-3, a significant increase of dipole moment $(+1.5$ and +1.8 Debyes for L-1 and L3 , respectively) and molecular volume $\left(+4.8 \AA^{3}\right.$ for L-1 and. +4.6 $\AA^{3}$ for L-3) occurs on passing from the GS to the TS geometries, as a consequence of the ring-opening process. Therefore, it seems reasonable to expect a significant solvent effect on the reaction rates, depending on the different permittivity and cohesive pressure of the solvents.

\section{Diastereomerization mechanism of compound L-2}

The theoretical analysis performed on Step I of the isomerisation reaction of the compound L-2, led to results very different to those achieved for L-1 and L-3. Starting from the most abundant conformer $\mathrm{L}-2-\mathrm{S}_{\mathrm{ax}}(\mathrm{BP}=60 \%)$, in which the axial $t$-butyl group increases the energy instability of GS much more than on the relevant TS, calculations estimated the very low ring-opening barrier of $22.3 \mathrm{kcal} \mathrm{mol}^{-1}$. This is a much lower value than that calculated for its flipped and minoritarian ( $\mathrm{BP}=40 \%)$ counterpart L-2-S $\mathrm{eq}_{\mathrm{eq}}\left(\Delta E_{\mathrm{L} \rightarrow \mathrm{M}}^{\#}=27.7 \mathrm{kcal} \mathrm{mol}^{-1}\right)$, but also too far from the value experimentally measured for the L-2 $\rightarrow$ M-2 process (25.5 $\mathrm{kcal} \mathrm{mol}^{-1}$ ). This result suggests that, for the compound L-2, the rate-limiting step of the isomerisation reaction should be the $\mathrm{ZW}$ F-rotation involved in Step II rather than the breaking of the $\mathrm{S}-\mathrm{C}_{\text {spiro }}$ bond (Schemes 4 and $\mathrm{S} 5$ in $\mathrm{ESI} \dagger$ ). In order to support this hypothesis, the barrier related to the ZW-F-rotation was estimated by assessing the energy profile resulting from the progressive change of the dihedral angle related to the $\mathrm{N}-\mathrm{N}-$ $\mathrm{C}_{\text {spiro }}-\mathrm{CH}$ torsional of the ZW-F structure, as shown in Fig. S1 of ESI. $\uparrow$ More details on this approach are given in ESI. $\dagger$ A barrier energy value of $26.3 \mathrm{kcal} \mathrm{mol}^{-1}$ for the most convenient rotation, deriving from the L-2-ZW-S $\mathrm{eq}_{\text {c }}$ conformer, was calculated, while an energy value of $26.9 \mathrm{kcal} \mathrm{mol}^{-1}$ was obtained from the ringflipped conformer L-2-ZW-S $\mathrm{S}_{\mathrm{ax}}$. These, in respect of the principle of the bottleneck (see $\mathrm{ESI}_{\dagger}$ ), are significantly close to the experimental value, within a difference of only $0.8-1.4 \mathrm{kcal} \mathrm{mol}^{-1}$. The same calculations on the ZW-F-rotation involved in Step II were carried out also for the compound L-1 and the TsC framework, in which the effect of the alkyl substituent on the cyclohexane moiety was expected to be less important or completely absent, respectively. In agreement with these expectations, the assessed lower energy barriers were $23.4 \mathrm{kcal} \mathrm{mol}^{-1}$ for L-1 and $23.1 \mathrm{kcal}$ $\mathrm{mol}^{-1}$ for TsC, thus confirming that only for compound L-2 the ZW-F-rotation is decisive in determining the final $\Delta G_{\mathrm{L} \rightarrow \mathrm{M}}^{\#}$ quantity. Furthermore, a progressive increase of surface area $\left(+6.5 \AA^{2}\right)$ and a modest increase of molecular volume $\left(+1.2 \AA^{3}\right.$, see Table $\mathrm{S} 2$ of ESI $\dagger$ ) were assessed by calculation on passing from the ground to the relevant transition states in the Step II. Thus, we could expect that the diastereomerization rate of L-2 should be differently affected by a change of solvent with respect to compounds L-1 and L-3. 


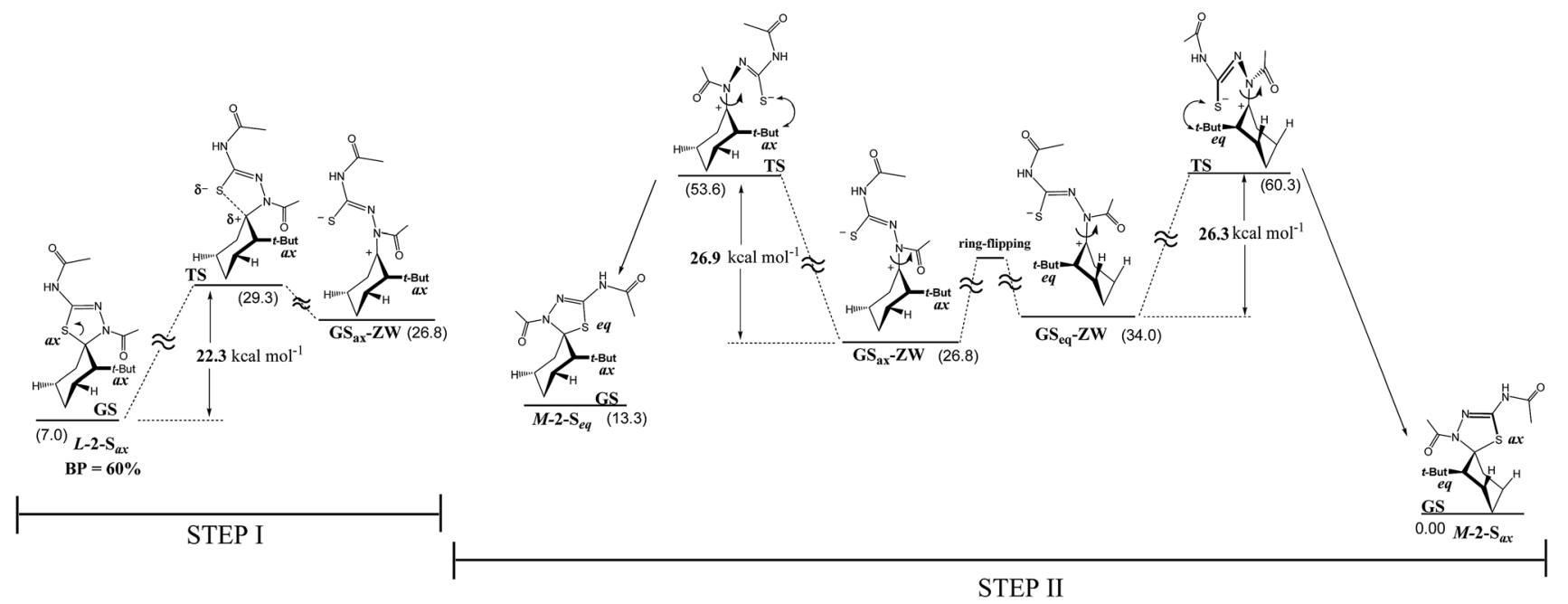

Scheme $4 \mathrm{~L} \rightarrow \mathrm{M}$ diastereomerization mechanism of compound L-2 derived by DFT calculations. In parentheses are reported the relative energy stabilities in $\mathrm{kcal} \mathrm{mol}^{-1}$ of the species with respect to that of the anancomeric $\mathrm{M}-2-\mathrm{S}_{\mathrm{ax}}$.

\section{Solvent effect on the diastereomerization barriers: LSER and DFT analysis}

The final step of our analysis was focused to get information on the solvent effects on the $\Delta G_{\mathrm{L} \rightarrow \mathrm{M}}^{\#}$ values. The data collected in Table 1 show that, on changing the solvent, the $\Delta G_{\mathrm{L} \rightarrow \mathrm{M}}^{\#}$ values change according to the following trend: $\Delta G_{\mathrm{L} \rightarrow \mathrm{M}}^{\# \mathrm{CHCl}_{3}}<\Delta G_{\mathrm{L} \rightarrow \mathrm{M}}^{\# \mathrm{AA}}<\Delta G_{\mathrm{L} \rightarrow \mathrm{M}}^{\# \mathrm{EA}}<\Delta G_{\mathrm{L} \rightarrow \mathrm{M}}^{\# \text { IPA }}$. From its inspection it is clear that cannot be derived any simple correlation between the differential solvation of ground and transition states governing the L-x $\rightarrow \mathbf{M}-\mathbf{x}$ interconversion and a single property of the solvent, such as permittivity or ability in establishing electrostatic, H-bond or dispersive interactions.

Therefore, we performed a Linear Solvation Energy Relationships (LSER) analysis, ${ }^{22,57-60}$ based on a set of multiparameter equations of the type

$$
\Delta G_{\mathrm{L} \rightarrow \mathrm{M}}^{\#}=\Delta G_{\mathrm{L} \rightarrow \mathrm{M}}^{\# \text { const }}+\sum f_{\mathrm{i}} D_{\mathrm{i}}
$$

where $\Delta G_{\mathrm{L} \rightarrow \mathrm{M}}^{\#}$ is the activation energy relative to the studied diastereomerizations in a given solvent $\left(\mathrm{CHCl}_{3}, \mathrm{EA}, \mathrm{AA}\right.$ and IPA), $\Delta G_{\mathrm{L} \rightarrow \mathrm{M}}^{\# \text { const }}$ is the activation energy for the reaction in absence of solvent effect, $D_{\mathrm{i}}$ is the descriptor of solvation interactions, and $f_{\mathrm{i}}$ its regression coefficient. As suggested by the already discussed calculations, concerning the stages of ring-opening (Step I) and subsequent ZW-F-rotation (Step II) of the overall distereomerization processes, the descriptors $D_{\mathrm{i}}$ were selected in order to take into suitable account the effects referable to changes of dipole moment $\left(\Delta \mu_{\mathrm{TS}-\mathrm{GS}}\right)$, molecular volume $\left(\Delta V_{\mathrm{TS}-\mathrm{GS}}\right)$ and molecular surface $\left(\Delta S_{\mathrm{TS}-\mathrm{GS}}\right)$ of the isomerizing species. On this basis, three different descriptors were used in the LSER regressions:

(i) the solvatochromic parameter $\pi^{*}$, sensible in monitoring solute-solvent dispersive, inductive and electrostatic interactions, directly related to the dipolarity and polarizability of the solvent, and thus to the extension of contact surface between solvent and solute; (ii) the solvent permittivity, $\varepsilon$, which is able to properly modulate merely electrostatic effects of aspecific type;

(iii) the Hildebrand parameter, $\delta_{\mathrm{H}}{ }^{2}$, which expresses the cohesive pressure of the solvent and thus the energy changes due to the generation of solvent cavities in which hosting the species involved into the analysed process.

We expected that the $\Delta \mu_{\text {TS-GS }}$ variations would be specifically monitored by the first two kinds of descriptors, while the $\Delta V_{\mathrm{TS}}$ Gs changes by the highly specialized $\delta_{\mathrm{H}}{ }^{2}$ parameter. The values of the three selected solvent parameters are collected in Table 2. More details on the performed LSER analyses are given in Experimental section and ESI. $\dagger$

\section{LSER results obtained on compounds L-1 and L-3}

Good correlations were obtained from the kinetic data for compounds L-1 $\left(R^{2}=0.9992\right.$, entry 4 of Table S3 $\left.\dagger\right)$ and L-3 $\left(R^{2}=\right.$ 0.9956 , entry 14 of Table S3†) when both descriptors $\pi^{*}$ and $\delta_{\mathrm{H}}{ }^{2}$ were used, according to eqn (3) and (4), respectively:

$$
\begin{aligned}
& \Delta G_{\mathrm{L} \rightarrow \mathrm{M}}^{\#}=25.60-7.04 \times \pi^{*}+0.72 \times \delta_{\mathrm{H}}^{2} \\
& \Delta G_{\mathrm{L} \rightarrow \mathrm{M}}^{\#}=26.15-8.18 \times \pi^{*}+0.59 \times \delta_{\mathrm{H}}^{2}
\end{aligned}
$$

The $\Delta G_{\mathrm{L} \rightarrow \mathrm{M}}^{\#}$ value decreases on increasing the dispersive, inductive and electrostatic solute-solvent interactions (negative value of the coefficient of the parameter $\pi^{*}$ ) while the increase of cavitational energy has the effect to increase the energy

Table 2 Descriptor of solvation interactions employed in the LSER analyses

\begin{tabular}{lccl}
\hline & Epsilon & $\delta_{\mathrm{H}}{ }^{2}$ & $\pi^{*}$ \\
\hline $\mathrm{CHCl}_{3}$ & 4.8 & 9.3 & 0.76 \\
$\mathrm{AA}$ & 20.7 & 10.3 & 0.742 \\
$\mathrm{EA}$ & 6 & 9.1 & 0.545 \\
$\mathrm{IPA}$ & 19.9 & 10 & 0.505
\end{tabular}


barrier (positive value of the coefficient of the parameter $\delta_{\mathrm{H}}^{2}$ ). This is coherent with the increase, in the ring-opening stage, of dipolarity and molecular volume of the TS with respect to the GS, as suggested by DFT calculations.

In a next step the solvent permittivity, $\varepsilon$, has been taken into account, instead of the $\pi^{*}$ descriptor, in the multiparametric analysis (eqn (5) and (6) for compound L-1 and L-3, respectively) and good correlations have been obtained, although lower than in eqn (3) and (4) (Table S3 in ESI $\dagger$ ).

$$
\begin{aligned}
& \Delta G_{\mathrm{L} \rightarrow \mathrm{M}}^{\#}=74.37+0.40 \times \varepsilon-5.32 \times \delta_{\mathrm{H}}^{2}\left(R^{2}=0.9942\right) \\
& \Delta G_{\mathrm{L} \rightarrow \mathrm{M}}^{\#}=82.18+0.46 \times \varepsilon-6.35 \times \delta_{\mathrm{H}}{ }^{2}\left(R^{2}=0.9701\right)
\end{aligned}
$$

It is important to stress as, in spite of their ineffectiveness as isolated descriptors of the solvent effects in monitoring the barrier, the parameters $\varepsilon$ and $\delta_{\mathrm{H}}{ }^{2}$ can instead act effectively and in complementary fashion when employed together.

In fact, both the descriptors were evaluated as statistically significant, with $t_{\mathrm{i}}$ values very close one to each other (i.e. of similar statistical weight, see entries 5 and 15 of Table S3†).

In conclusion, the greater is the ability of the solvent to establish good aspecific electrostatic interactions with the solute and to keep down the cost of energy need to host the solubilized molecules, the greater is the rate of the diastereomerization of the compounds L-1 and L-3. In this context, evidently, dispersive and inductive interactions play a minor role and act in a similar extent in all solvents.

Eventually, an approximate quantification of the role played by the four considered solvents in affecting the relevant L-x $\rightarrow$ M-x isomerization barriers has been achieved as the percentage contribution that the $\sum f_{\mathrm{i}} D_{\mathrm{i}}$ amount affords to the $\Delta G_{\mathrm{L} \rightarrow \mathrm{M}}^{\#}$ quantities. Thus, for the case of the L-1 $\rightarrow$ M-1 and L-3 $\rightarrow$ M-3 processes the $\sum f_{\mathrm{i}} D_{\mathrm{i}}$ contribution was assessed in the average value of $\sim 30 \%$.

\section{LSER and DFT results obtained on compound L-2}

For compound L-2, the employment of the couples of $\pi^{*}-\delta_{\mathrm{H}}{ }^{2}$ and $\varepsilon-\delta_{\mathrm{H}}{ }^{2}$ descriptors inside equations of type 2 was not sufficiently significant under a statistical point of view (entry 9 and 10 of Table S3 in ESI $\dagger$ ). This is in agreement with the different mechanism suggested by the theoretical investigation for the diastereomerization of L-2 with respect to L-1 and L-3.

However, the good correlation obtained from the LSER analysis when $\pi^{*}$ was used as the unique descriptor $\left(R^{2}=\right.$ 0.9378 , entry 6 of Table S3†) suggests the involvement, in the slow step of the L-2 $\rightarrow$ M-2 isomerization reaction, of generic electrostatic, dispersive and inductive solute-solvent interactions which, evidently, act in a different way on the GS and TS structures.

Indeed, the assessed increase of the surface area on passing from the GS geometry L-2-ZW-S eq to the related TS by ZW-Frotation (see the last part of the subsection "Diastereomerization mechanism of compound L-2"), is coherent with the establishment of more extensive inductive and dispersive solute-solvent interactions for TS than for GS. This can account for the decrease of the $\Delta G_{\mathrm{L} \rightarrow \mathrm{M}}^{\#}$ barrier experimentally observed in response to an increase of the polarizability of the solvent, as suggested by the descriptor $\pi^{*}$ in the LSER analysis. In order to rationalize, by theoretical approach, the experimental kinetic trend of the L-2 $\rightarrow$ M-2 isomerization in the different solvents, the GS and TS geometries involved in Step II of the process and modelled in chloroform, were optimized also in ethyl acetate and 2-propanol (Table S2 in ESI $\dagger$ ). The calculated values of energy barriers in these additional solvents $\left(\Delta G_{\mathrm{L} \rightarrow \mathrm{M}}^{\# \mathrm{EA}}=26.49\right.$ kcal mol${ }^{-1}$ and $\Delta G_{\mathrm{L} \rightarrow \mathrm{M}}^{\# \mathrm{IPA}}=28.00 \mathrm{kcal} \mathrm{mol}^{-1}$ ) are in very good agreement with the experimental data, differing by only -0.35 and $+0.22 \mathrm{kcal} \mathrm{mol}^{-1}$, respectively. These results, again, play in favour of a different slow step for the L-2 $\rightarrow$ M-2 isomerization, which do not involve the ring-opening. Finally, in comparison with the equivalent kind of information already achieved for the L-1 $\rightarrow$ M-1 and L-3 $\rightarrow$ M-3 processes, the percentage contribution that the $f \pi^{*}$ term of each solvent provides to the relevant $\Delta G_{\mathrm{L} \rightarrow \mathrm{M}}^{\#}$ barrier is a bit smaller, within the range $14-23 \%$.

\section{Assessment of the stereolability affecting compounds L-1, L-2 and $L-3$ in water}

In consideration of the possible applications that the here studied spiro-1,3,4-thiadiazoline derivatives could have as potential drugs, we found interesting to perform a final estimation of their tendency to undergo irreversible diastereomerization from the $\mathrm{L}$ to the $\mathrm{M}$ forms in water, that is to say, in the solvent that any drug met in physiological conditions. The intent was achieved by re-optimizing through DFT calculations in water the geometries of the GS and TS states involved in the same rate-limiting steps already identified for each of them in chloroform solution. The achieved findings (Table $\mathrm{S} 2 \dagger$ ) suggested that, with respect to what experimentally observed in the four investigated media, water may appreciably decrease the activation barrier characterizing the Step I of the irreversible $\mathrm{L} \rightarrow \mathrm{M}$ interconversion of compound $\mathrm{L}-\mathbf{1}\left(\Delta E_{\mathrm{L} \rightarrow \mathrm{M}}^{\#}=26.6 \mathrm{kcal}\right.$ $\left.\mathrm{mol}^{-1}\right)$ and compound L-3 $\left(\Delta E_{\mathrm{L} \rightarrow \mathrm{M}}^{\#}=24.9 \mathrm{kcal} \mathrm{mol}^{-1}\right.$, passing through the continuous conversion of $\mathrm{L}-3-\mathrm{S}_{\mathrm{ax}}$ in $\mathrm{L}-3-\mathrm{S}_{\mathrm{eq}}$ ). Instead, for the species L-2 a moderate reduction of the assessed $\Delta E_{\mathrm{L} \rightarrow \mathrm{M}}^{\#}$ quantity was found in water only with respect to the equivalent data measured in the solvents EA and IPA $\left(\Delta E_{\mathrm{L} \rightarrow \mathrm{M}}^{\#}=\right.$ $26.3 \mathrm{kcal} \mathrm{mol}^{-1}$ ). The substantial reliability of the estimated barriers is confirmed by their compatibility with the relevant trends assessable through the equations derived by LSER analyses that involve or not the new activation data calculated in water (i.e. eqn (3) and (4) or the new ones obtainable through multiple regressions inclusive of the just discussed barriers in water). In the whole, then, it seems possible to generalize that also in water, at room temperature, the studied L-x compounds are expected to effectively retain their configuration at $\mathrm{C}_{\text {spiro }}$ carbon, being the shorter half-life time of diastereomerization (i.e. that of L-3) evaluable as amounting to 4.6 days.

\section{Conclusions}

An experimental and theoretical in-depth study has been performed in order to achieve kinetic and mechanistic information about the stereolability of three chiral 1,3,4-thiadiazoline-spirocyclohexyl derivatives (L-1, L-2 and L-3 of Fig. 1). 
The rationalization of the obtained kinetic data has been supported by DFT calculations, pointing out that two different slow steps for the diastereomerization reaction could be involved, depending on type and position of the substituent alkyl group on the cyclohexane moiety.

The slow step can be identified with the heterocycle ringopening, for the compounds L-1 and L-3 (i.e. the Step I of the overall process) or with the $180^{\circ}$ rotation of the zwitterionic framework resulting from the heterocycle ring-opening (still linked to the $\mathrm{C}_{\text {spiro }}$ atom) for the compound L-2 (i.e. the Step II of the overall process).

The solvent effects on the rate of the isomerisation reactions have been rationalized by LSER analyses and DFT calculations. The obtained results suggest that for compounds L-1 and L-3 the increase of dipolarity and molecular volume resulting from the heterocycle ring-opening acts in opposition one to each other in affecting the $\Delta G_{\mathrm{L} \rightarrow \mathrm{M}}^{\# \mathrm{x}}$ barrier, with the second one (which slows down the process) slightly prevailing over the first one. Overall, in apolar solvents the stereolability of the investigated compounds increases while in protic solvents the activation barriers of the diastereomerization reactions increases. The compound L-2 behaves differently. LSER data suggested that, for this species, the increase in stereolability, by changing from less to more polarizable solvents, depends on differential dispersive and inductive interactions established by the solvent with the ground and the transition state geometries of the slow Step II of the reaction pathway. As indicated by calculations, probably this is due to the increase of surface area suffered by the GS structure when it approaches its related TS.

We believe that the here presented elucidation of the reaction mechanism, of the effects that structural factors can exert over it, as well as of the influence that a change of solvent may have on the diastereomerization barrier of the species formed under kinetic control, may be of great importance in the perspective to make rational the design of new chiral bioactive thiadiazoline-spiro-cyclohexyl derivatives. Indeed, a stereoselective synthesis of their diastereomeric forms become possible simply switching the reaction conditions from a kinetic to a thermodynamic control, and vice versa, making also possible an effective modulation of their spiro-junction lability by planning appropriate substitutions on the cyclohexane ring.

\section{Acknowledgements}

This work was conducted with financial support from the Sapienza University contract no. C26A143MYA (2014).

\section{Notes and references}

1 A. C. Albert, F. G. Joyce, D. S. Arthur, R. M. Donald, F. S. William, B. S. Joseph, J. G. Martin, W. F. Robert and D. M. Gerald, J. Med. Chem., 1976, 19, 1142.

2 H. Cederlund and P.-A. Mardh, J. Antimicrob. Chemother., 1993, 32, 355.

3 R. Rios-Santamarina and J. Garcia-Domenech, Eur. J. Pharm. Sci., 2004, 22, 271.
4 R. S. Vartanyan, J. Pharm. Chem., 1984, 18, 736.

5 H. I. El-Subbagh, S. M. Abu-Zaid, M. A. Mahran, F. A. Badria and A. M. Al-obaid, J. Med. Chem., 2000, 43, 2915.

6 I. G. Mobio, A. T. Soldatenkov, V. O. Federov, E. A. Ageev, N. D. Sergeeva, S. Lin, E. E. Stashenku, N. S. Prostakov, E. Andreeva and L. Khim, Farm. Zh., 1989, 23, 421.

7 A. R. Katritzky and W. J. Fan, J. Org. Chem., 1990, 55, 3205.

8 A. Naya, M. Ishikawa, K. Matsuda, K. Ohwaki, T. Saeki, K. Naguchi and N. Ohtake, Bioorg. Med. Chem., 2003, 11, 875.

9 R. V. Perumal, M. Adiraj and P. Shanmugapandiyan, Indian Drugs, 2001, 38, 156.

10 K. Chibale, M. Visser, D. von Schalkwyk, P. J. Smith, A. Saravanamuthu and A. H. Fairlamb, Tetrahedron, 2003, 59, 2289.

11 A. Naya, Y. Sagara, K. Ohwaki, T. Saeki, Y. Ichasawa, K. Naguchi and N. Ohtake, J. Med. Chem., 2001, 44, 1429.

12 C. R. Ganellin and R. G. W. Spickett, J. Med. Chem., 1965, 8, 619.

13 S. Chatterjee, M. Iqbal, J. C. Kauer, J. P. Mallamo, S. Senadhi, S. Mallya, D. Bozyczko-Coyne and R. Siman, Bioorg. Med. Chem. Lett., 1996, 6, 1619.

$14 \mathrm{~J}$. Wichmann, K. Bleicher, E. Vieira, T. Woltering, F. Knoflach and V. Mutel, Farmaco, 2002, 57, 989.

15 J. W. Daly, in The Alkaloids, ed. G. A. Cordell, Academic press, Sandiego, CA, 1998, p. 141.

16 C.-P. Wu, D. A. Van Schalkwyk, D. Taylor, P. J. Smith and K. Chibale, Int. J. Antimicrob. Agents, 2005, 26, 170.

17 E. Vieira, J. Huwyler, S. Jolidon, F. Knoflach, V. Mutel and J. Wichmann, Bioorg. Med. Chem., 2005, 15, 4628.

18 T. Shiro, T. Fukaya and M. Tobe, Eur. J. Med. Chem., 2015, 97, 397.

19 S. Carradori, R. Cirilli, S. Dei Cicchi, R. Ferretti, S. Menta, M. Pierini and D. Secci, J. Chromatogr. A, 2012, 1269, 168.

20 J. J. Li, X. M. Liang, S. H. Jin, J. J. Zhang, H. Z. Yuan, S. H. Qi, F. H. Chen and D. Q. Wang, J. Agric. Food Chem., 2010, 58, 2659.

21 R. Crossley, Chirality and the Biological Activity of Drugs, CRC Press, New York, 1995.

22 H.-J. Schneider and A. K. Yatsimirsky, Principles and Methods in Supramolecular Chemistry, Wiley \& Sons, New York, 2000.

23 M. I. Page and W. P. Jencks, Proc. Natl. Acad. Sci. U. S. A., 1971, 68, 1678.

24 M. I. Page, Chem. Soc. Rev., 1973, 2, 295.

25 W. P. Jencks, Proc. Natl. Acad. Sci. U. S. A., 1978, 78, 4046.

26 G. Haberhauer, S. Ernst and C. Wilch, Chem.-Eur. J., 2011, 17, 8643.

27 H. Ito, T. Abe and K. Saigo, Angew. Chem., Int. Ed., 2011, 50, 7144.

28 I. Alkorta and J. Elguero, Tetrahedron: Asymmetry, 2010, 21, 437.

29 G. S. Singh and Z. Y. Desta, Chem. Rev., 2012, 112, 6104.

30 B. Wunsch, Curr. Pharm. Des., 2012, 18, 930.

31 L. Zhou, J. Zhao, T. Shan, X. Cai and Y. Peng, Mini-Rev. Med. Chem., 2010, 10, 977.

32 A. I. Almansour, R. S. Kumar, F. Beevi, A. N. Shirazi, H. Osman, R. Ismail, T. S. Choon, B. Sullivan, 
K. McCaffrey, A. Nahhas, K. Parang and M. A. Ali, Molecules, 2014, 19, 10033.

33 H. N. Hafez, M. I. Hegab, I. S. Ahmed-Farag and A. B. elGazzar, Bioorg. Med. Chem. Lett., 2008, 18, 4538.

34 S. Umamatheswari, B. Balaji, M. Ramanathan and S. Kabilan, Bioorg. Med. Chem. Lett., 2010, 20, 6909.

35 C. De Monte, S. Carradori, D. Secci, M. D'Ascenzio, P. Guglielmi, A. Mollica, S. Morrone, S. Scarpa, A. M. Aglianò, S. Giantulli and I. Silvestri, Eur. J. Med. Chem., 2015, 105, 245.

36 S. Menta, S. Carradori, D. Secci, C. Faggi, L. Mannina, R. Cirilli and M. Pierini, J. Org. Chem., 2015, 80, 11932.

37 E. Eliel, S. H. Wilen and L. N. Mander, Stereochemistry of Organic Compounds, Wiley \& Sons, New York, 1993.

38 M. Anteunis, D. Tavernier and F. Borremans, Bull. Soc. Chim. Belg., 1966, 75, 396.

39 T. Benincori, V. Bonometti, R. Cirilli, P. R. Mussini, A. Marchesi, M. Pierini, T. Pilati, S. Rizzo and F. Sannicolò, Chem.-Eur. J., 2013, 19, 165.

40 B. Gallinella, L. Bucciarelli, L. Zanitti, R. Ferretti and R. Cirilli, J. Chromatogr. A, 2014, 1339, 210.

41 R. Ferretti, B. Gallinella, F. La Torre, L. Zanitti, L. Turchetto, A. Mosca and R. Cirilli, J. Chromatogr. A, 2009, 1216, 5385.

42 T. Zhang, D. Nguyen, P. Franco, Y. Isobe, T. Michishita and T. Murakami, J. Pharm. Biomed. Anal., 2008, 46, 882.

43 O. Tishchenko and D. G. Truhlar, J. Phys. Chem. Lett., 2012, 3, 2834.

44 I. Hermans, P. Jacobs and J. Peeters, Phys. Chem. Chem. Phys., 2008, 10, 1125.

45 Y. Zhao and D. G. Truhlar, Theor. Chem. Acc., 2008, 120, 215.

46 R. Bernini, F. Crisante, P. Gentili, S. Menta, F. Morana and M. Pierini, RSC Adv., 2014, 4, 8183.
47 G. Cancelliere, A. Ciogli, I. D'Acquarica, F. Gasparrini, J. Kocergin, D. Misiti, M. Pierini, H. Ritchie, P. Simone and C. Villani, J. Chromatogr. A, 2010, 1217, 990.

48 R. Cirilli, R. Costi, R. Di Santo, F. La Torre, M. Pierini and G. Siani, Anal. Chem., 2009, 81, 3560.

49 R. Cirilli, R. Ferretti, F. La Torre, D. Secci, A. Bolasco, S. Carradori and M. Pierini, J. Chromatogr. A, 2007, 1172, 160. 50 C. Wolf, Dynamic Stereochemistry of Chiral Compounds: Principles and Applications, RSC Publishing, London, 2008. 51 C. Wolf, Chem. Soc. Rev., 2005, 34, 595.

52 A. Fontana, P. De Maria, G. Siani, M. Pierini, S. Cerritelli and R. Ballini, Eur. J. Org. Chem., 2000, 1641.

53 A. Dalla Cort, F. Gasparrini, L. Lunazzi, L. Mandolini, A. Mazzanti, C. Pasquini, M. Pierini, R. Rompietti and L. Schiaffino, J. Org. Chem., 2005, 70, 8877.

54 F. Gasparrini, M. Pierini, C. Villani, P. De Maria, A. Fontana and R. Ballini, J. Org. Chem., 2003, 68, 3173.

55 F. Gasparrini, I. D'Acquarica, M. Pierini and C. Villani, J. Sep. Sci., 2001, 24, 941.

56 W. Braun, J. T. Herron and D. K. Kahaner, Int. J. Chem. Kinet., 1988, 20, 51.

57 M. J. Kamlet, J.-L. M. Abboud and R. W. Taft, An Examination of Linear Solvation Energy Relationships, Progress in Physical Organic Chemistry, Wiley \& Sons, 1981, vol. 13.

58 M. J. Kamlet, J.-L. M. Abboud and R. W. Taft, J. Am. Chem. Soc., 1977, 99, 6027.

59 D. Kotoni, M. Piras, W. Cabri, F. Giorgi, A. Mazzanti, M. Pierini, M. Quaglia, C. Villani and F. Gasparrini, $R S C$ Adv., 2014, 4, 32847.

60 W. Cabri, I. D'Acquarica, P. Simone, M. Di Iorio, M. Di Mattia, F. Gasparrini, F. Giorgi, A. Mazzanti, M. Pierini, M. Quaglia and C. Villani, J. Org. Chem., 2011, 76, 1751. 